\title{
Caracterización petrográfica del batolito de Aracataca sector sur- occidental de la Sierra Nevada de Santa Marta.
}

Petrographic characterization of the Aracataca's batholith south-west sector of the Sierra Nevada of Santa Marta

Dianelys Corzo Hernández Autor de correspondencia Fundación Universitaria del Área Andina, Valledupar, Colombia.

dicorzo@estudiantes.areandina.edu.

$\mathrm{CO}$

Greys Paola Habid Vega Fundación Universitaria del Área Andina, Valledupar, Colombia..

Luis Eduardo Moscote Mendoza Fundación Universitaria del Área Andina, Valledupar, Colombia.
Luis Carlos Tapia Vela

Autor de correspondencia Fundación Universitaria del Área Andina, Valledupar, Colombia.. 


\section{Resumen}

El Batolito de Aracataca es una unidad de composición félsica a intermedia constituida por cuerpos ígneos intrusivos de las facies Granodioritas, Cuarzomonzonitas y Tonalitas que afloran en el piedemonte Occidental de la Sierra Nevada de Santa Marta sector Sur-Este del municipio de Fundación, departamento del Magdalena. El estudio se realiza con el fin de definir las variaciones composicionales y asociaciones mineralógicas presentes en cada una de las litológicas que conforman esta unidad. Los estudios aquí presentados incluyen la descripción macroscópica de facies, análisis petrográfico a través de luz trasmitida y Difracción de rayos $x$. Los resultados de estos análisis indican variaciones litológicas de las facies texturales dentro del Batolito en el momento de su formación, arrojando afectaciones en los componentes minerales de la roca, se asocian a la incidencia de actividad tectónica y a la ocurrencia de fluidos hidrotermales. Los análisis realizados evidencian que los cambios (texturales, composicionales) y alteraciones de los minerales en las rocas están asociados a los eventos magmáticos durante su proceso de formación y el dominio de fluidos hidrotermales..

\section{Palabras Claves:}

Sierra Nevada de Santa Marta, Batolito de Aracataca, microscopia óptica, análisis petrográfico, difracción de Rayos $X(D R X)$.. 


\section{Abstract}

Aracataca's Batholith is a unit of felsic to intermediate composition constituted by intrusive igneous bodies of the granodiorites facies, quartzmonzonites and tonalities that appear in the Sierra Nevada de Santa Marta (Snow Mountain of Santa Marta) foothill in the South-East sector of the Municipality of Fundación, Department of Magdalena. This study is carried out in order to obtain information based on the results obtained from the performance of petrographic analysis made to samples obtained from the Aracataca's Batholith. This study is carried out in order to obtain a detailed

Keywords:

Sierra Nevada de Santa Marta,

Aracataca's

Batholith,

petrografica

characterization,

petrographic

analysis,

diffraction ray- $X$

$(D R X)$ petrographic characterization of the mineral associations in each of the lithological variations that make up this unit. The studies presented include the description of lithological facies based on petrographic analysis, which presents mineralogical characteristics, which make possible to determine the compositional and textural character of each lithology, as well as the type of alteration (Propiliticas and Sericiticas) that affect the appearance of the crystals in the rocks. The results of these analyses indicate the variation of textural facies within the Batholith at the time of its formation, producing some effects in the mineral components of the rock, which are associated with the incidence of tectonic activity and the occurrence of hydrothermal fluids. Also describes the results of trials of diffraction of Rays X (DRX); in these analyses, it is evident that changes and alterations of the mineral are associated with magmatic events during its formation process and the domain of hydrothermal fluids. 


\section{Introducción}

El macizo de la Sierra Nevada de Santa Marta corresponde a un sistema montañoso que ha estado sometido a varios eventos tectónicos [1]. Estos son principalmente: el Evento Metamórfico Proterozoico (Meso y Neoproterozoico), el Evento Metamórfico Paleozoico Temprano (Ordovícico y Silúrico), y el Evento Magmático Jurásico Tardío. Estructuralmente, se encuentra demarcado por los sistemas de la falla Santa Marta-Bucaramanga al Occidente, la falla de Oca al Norte y el lineamiento del Cesar al Suroriente (ver Figura 2)

Las rocas intrusivas dominan la mayor parte de la Sierra Nevada de Santa Marta (SNSM), donde aflora una diversidad de litologías con distintos procesos de formación. De forma precisa, la región Sur de la SNSM está constituida por alternancias de varios tipos de rocas félsicas, intermedias y máficas, variando composicionalmente en facies granodioriticas y cuarzomonzoniticas. Localmente, en la sección Sur-Occidental afloran cuerpos ígneos intrusivos pertenecientes al Batolito de Aracata (Jar), y distribuidos hacia el Este del municipio de Fundación, departamento de Magdalena, orientado en dirección SN, S-SW y N-NE.

Esta unidad fue descrita principalmente por Tschanz et al (1969), quienes establecieron que este batolito hace parte del denominado Cinturón Central de Batolitos Jurásicos [2], el cual corresponde a un cinturón continuo compuesto por rocas intrusivas de composición félsica a intermedia.

La realización de este trabajo parte del interés de conocer y diferenciar, a partir de datos cuantitativos, la composición mineralógica y petrográfica del Batolito de Aracataca en el sector Sur-Este de los municipios de Aracataca y Fundación en el departamento de Magdalena. También se pretende establecer las implicaciones petrogenéticas del contexto geodinámico regional. Se toma como base la importancia que representa esta unidad por ser parte del cinturón de batolitos jurásicos que se distribuyen en la Sierra Nevada de Santa Marta [2]. La definición de las composiciones de estas rocas se apoya en la realización de ensayos de 
difracción y la elaboración e interpretación de secciones delgadas que son fundamentales en los análisis microscópicos correspondientes a estudios petrográficos. Así pues, este estudio se enfoca en conocer la composición mineralógica de las facies litológicas del Batolito de Aracataca con el fin de relacionar dichas asociaciones minerales con los posibles procesos evolutivos que pudo haber sufrido el Plutón durante su formación, además de realizar un aporte a investigaciones futuras sobre la geología y petrografía que caracteriza esta unidad.

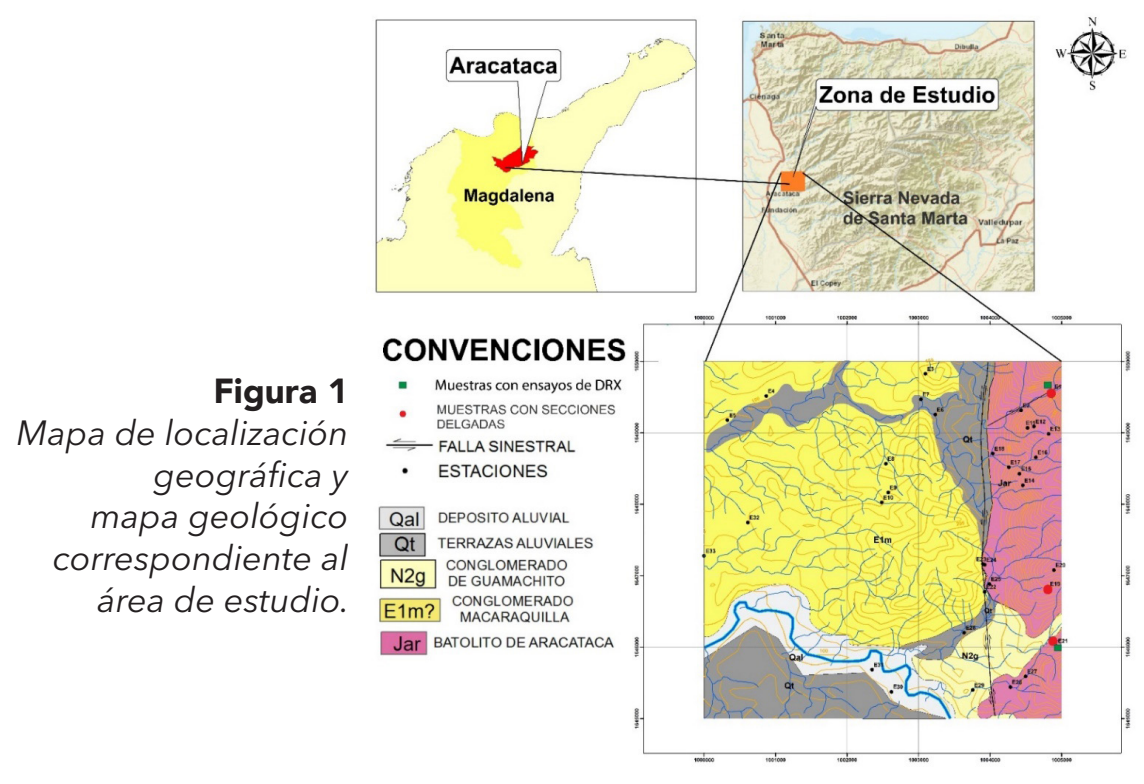




\section{Localización}

Geológicamente, la zona de estudio se ubica al pie de la vertiente occidental de la Sierra Nevada de Santa Marta (sector Sur-Este del municipio de Fundación, departamento del Magdalena). Comprende un área de $25 \mathrm{Km}^{2}$, proyectado desde la plancha topográfica 26 IIIC (Instituto Geográfico Agustín Codazzi; escala 1:25000). Las coordenadas que enmarcan el área corresponden al NW: $1 ` 000.000$, 1`650.000; NE: 1`005.000, 1`650.000; SW: 1`000.000, 1`645.000; y SE: 1`005.000, $1 \asymp 645.000$.

Para acceder a la zona de estudio se debe tomar la vía 80, que conduce del municipio de Valledupar, Cesar, a la ciudad de Santa Marta, Magdalena. Posteriormente, al llegar al municipio de El Copey sobre el margen derecho de la vía principal, se avanzan $33 \mathrm{~km}$ hasta llegar al corregimiento de Santa Rosa de Lima, perteneciente al municipio de Fundación (ver Figura 1).

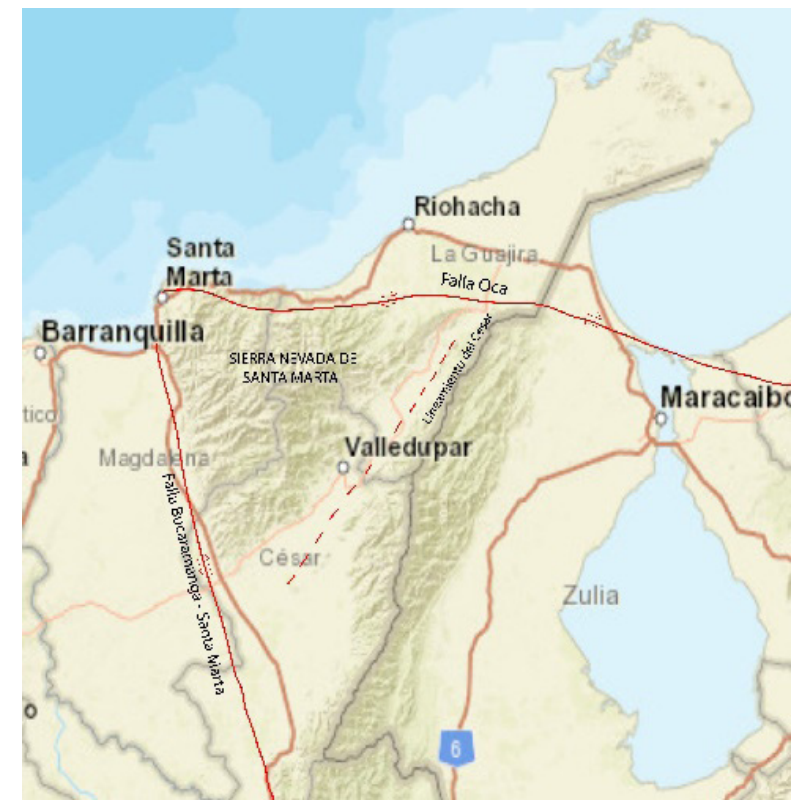

Figura 2.

Mapa estructural regional de la Sierra Nevada de Santa Marta. 


\section{Metodología}

Este estudio se apoya en un trabajo de campo, en el cual se realizó un recorrido cartográfico de la zona basado en análisis geomorfológicos, litológicos y estructurales. Durante esta fase se realizó un reconocimiento geológico, cartografía geológica, muestreo de diferentes unidades litológicas y toma de datos estructurales. La fase de laboratorio se basó en un análisis macroscópico y microscópico de las muestras recolectadas en campo.

Durante el estudio macroscópico se describieron, además, las características mineralógicas de las rocas, las cuales posibilitan determinar las variaciones composicionales, asociaciones minerales, tipos de texturas y alteraciones.

La definición de las composiciones de cada facie está apoyada en la interpretación de secciones delgadas y elaboración de ensayos de difracción de rayos $X$. Durante el estudio de las muestras mediante microscopia óptica, se utilizó un estereoscopio marca Motic SMZ-168 y un microscopio de luz transmitida marca Optiks XPL-1530. Los análisis fueron realizados en el Laboratorio de Mineralogía y Cristalografía de la Fundación Universitaria del Área Andina sede Valledupar. Para los análisis de DRX, se utilizó un difractómetro de polvo Bruker D8 Advance con Geometría DaVinci, bajo consideraciones de medición propias del laboratorio de rayos $\mathrm{X}$ de la escuela de Geología y Química de la Universidad Industrial de Santander (UIS). El artículo se realizó cuenta partir de los análisis cualitativos y cuantitativos de las fases presentes en los especímenes seleccionados de las muestras estudiadas. 


\section{Contexto geológico y antecedentes}

Las unidades de roca aflorantes en el sector suroccidental de la Sierra Nevada de Santa Marta hacen parte de los cuerpos ígneos intrusivos perteneciente al Batolito de Aracataca, que se formaron por la actividad de una zona de subducción a lo largo de un cinturón magmático calcoalcalino de edad jurásica. Las descripciones a detalle de estas unidades ígneas son reportadas originalmente por Tschanz et al [3], y entre las litologías reconocidas en el área de estudio se destacan también los cuerpos sedimentarios pertenecientes al Valle Inferior del Magdalena, que son los de mayor abundancia en la región.

Estos últimos se relacionan con el levantamiento de la Sierra Nevada de Santa Marta, que produjo una depósito de sedimentos en forma de abanicos aluviales de origen continental. Los mismos cuerpos sedimentarios aludidos se encuentran dispuestos en las partes más bajas de los frentes montañosos, y estaban compuestos por capas gruesas de conglomerados clasto-soportados con gradación normal, que presentan un tamaño de arena gruesa a cantos, con clastos que proceden de rocas cristalinas y matriz tamaño arena. Hernández et al (2002) le asigna una edad entre el Paleoceno y el Eoceno, que correspondería a la Unidad Conglomerados de Macaraquilla.

En el lapso de los periodos Mioceno-Plioceno se depositaron sedimentos originados por flujos rápidos en paleocanales de ambiente submarino en las depresiones de áreas marinas cercanas a los levantamientos que se produjeron en la Sierra Nevada de Santa Marta, donde, además, se desarrollaron ciclos regresivos oscilatorios. A estos depósitos se han asociado los conglomerados matrizsoportados compactos, constituidos por cantos subredondeados de tamaño guijo y guijarro, provenientes de rocas plutónicas de composición granítica, volcánica y metamórfica; su matriz es de arenita con cemento ferruginoso y pertenece a los Conglomerados de Guamachito [2]. 


\section{Batolito de Aracataca (Jar)}

Esta unidad se distribuye sobre la región E del área de estudio, ocupando aproximadamente $5 \mathrm{~km} 2$ de esta, extendiéndose en sentido Norte-Sur. La unidad corresponde a uncuerpoígneo intrusivo con características distintivas de un magma de composición félsica a intermedia y por consiguiente se constituye de rocas ígneas intrusivas con variaciones composicionales; litológicamente, se diferencian muestras de rocas asociadas a facie de granodioritas, facie de cuarzomonzonitas y facie de tonalitas.

El batolito representa el enfoque principal para la realización del presente estudio, por lo cual se describe con mayor amplitud durante el avance del trabajo. 


\section{Geología estructural}

El comportamiento estructural de las unidades de roca que constituyen el área en estudio se ven afectadas principalmente por el predominio de una falla, extendida en dirección SN y denominada Falla Marimonda, y por un lineamiento desprendido de esta falla principal, dispuesto en sentido NE. Estas fallas, ubicadas hacia la parte oriental del área de estudio, se proyectan hacia el margen occidental de la Sierra Nevada de Santa Marta, y presenta evidencia de cortos desplazamientos sinestrales [2].

\section{Lineamiento de la Falla Marimonda}

Como ya se dijo, este lineamiento se extiende en sentido NE sobre la parte $\mathrm{N}$ de la zona de estudio y atraviesa la unidad Batolito de Aracataca, marcando topografías en su trazo. En la parte izquierda de la falla se presentan colinas subangulares dispuestas de forma alargada y generan escarpes. Aquí se manifiestan redes de drenajes subparalelos y subdendríticos. Y hacia la parte derecha de la falla, se aprecian pendientes inclinadas con drenajes subparalelos, que están afectados por procesos erosivos y desprendimientos de bloques desde la parte superior de las colinas (ver Figura 2).

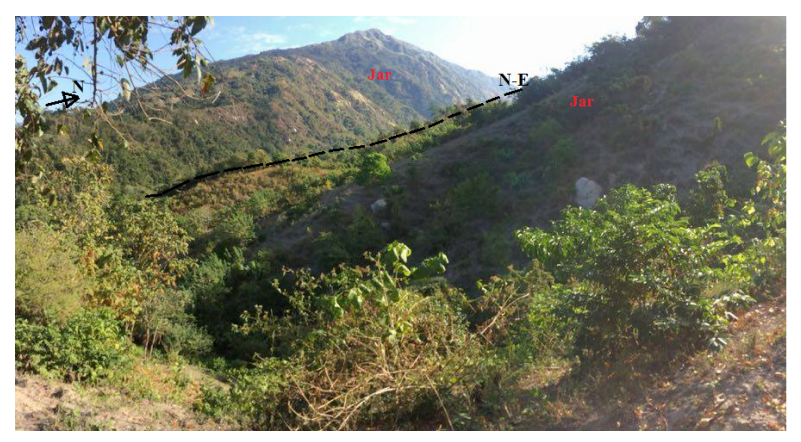

\section{Figura 2.}

Lineamiento de la Falla

Marimonda que se extiende en dirección Nor- Este, cortando la unidad de rocas ígneas pertenecientes al Batolito de Aracataca (Jar). 


\section{Falla Marimonda}

Es una estructura rectilínea de aproximadamente $30 \mathrm{~km}$ de longitud ubicada en dirección SN con relación al área de trabajo comprendida en este trabajo. Se encuentra cubierta por depósitos cuaternarios, cuyo trazo corresponde al sendero de la vía principal que comunica con las poblaciones rurales en la zona.

En la realización de una estación geomorfológica (DGL 020), realizada sobre la cima de una colina a una altura aproximada de $320 \mathrm{msnm}$, se diferenciaron indicadores geomorfológicos del trazo de la falla, y corresponden a domos deflectados o lomos de ballena (ver Figura 3). Estos domos se localizan en dirección NS (respecto a la ubicación de la estación) y descienden o se deflectan en sentido SE. Por la disposición de estas geoformas y las estructuras generadas, se consideró que esta falla transcurre por el límite de la variación topográfica ocasionando escarpes.

Figura 3.

Trazo de la Falla Marimonda que se extiende en sentido $N$-S representado por la línea de color negro, el cual atraviesa las estructuras de domos deflectados que están simbolizados por las líneas de color amarillo, cortando la unidad Batolito de Aracataca (Jar) y los Depósitos Cuaternarios (Qal)

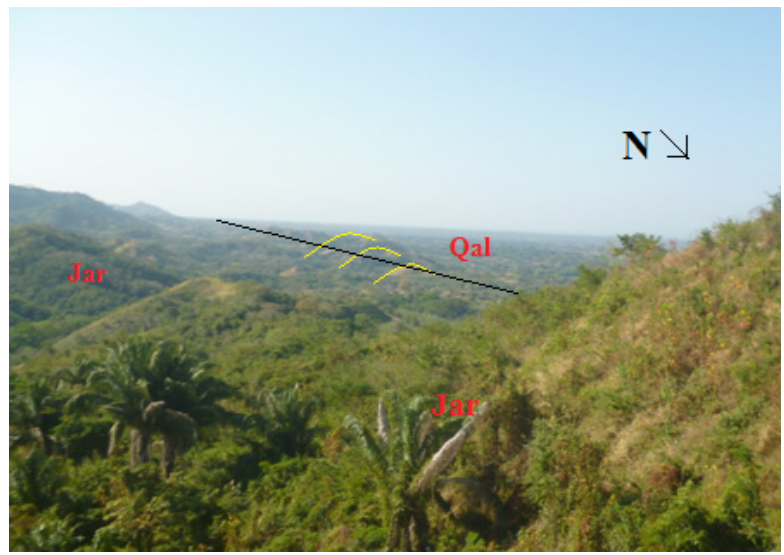




\section{Análisis de resultados}

\section{Análisis petrográfico}

El análisis petrográfico se realizó a tres secciones delgadas que corresponden a las muestras más representativas del Batolito de Aracataca ubicado en dirección $\mathrm{N}-\mathrm{E}$ del área de estudio, con el fin de determinar las características texturales y mineralógicas de las rocas. La unidad del Batolito de Aracataca muestra variaciones composicionales evidenciadas en la presencia predominante de granodioritas, cuarzomonzonitas y tonalitas (ver Figura 4).

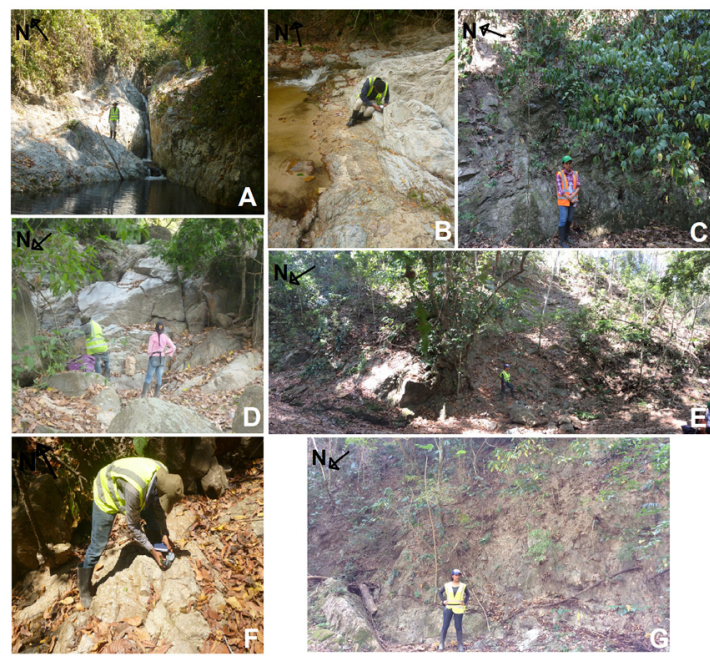

Figura 4.

Afloramientos representativos del Batolito de Aracataca donde se observan las variaciones de facies litológicas pertenecientes a esta unidad. Las imágenes A. B Y D corresponden a aforamientos representativos de la facie Granodiorita. (A) Se encuentra ubicado sobre la Quebrada Seca en la zona NE del área de estudio, en cercanías a la finca La Esperanza. (B) Se ubica a 10 $m$ del camino principal del área de estudio en la región $N E$, aflorando en la Quebrada Seca a aproximadamente $500 \mathrm{~m}$ de la finca Bendición de Dios. (D) Se localiza en un drenaje de la Quebrada Seca, en cercanías a la vereda "Entra Si Puedes", al margen derecho del camino principal en sentido NW. Las imágenes Ey F hacen parte de la Facie Cuarzomonzonita y se encuentran localizadas dentro de drenajes pertenecientes a la quebrada El Invento, ubicada en la región NW del área. Las imágenes Cy G corresponden a afloramientos representativos de la Facie Tonalita, se localizan en cercanías a la vereda Nuevo Horizonte sobre un drenaje que conduce al río San Sebastián de Fundación en la región SE del área de estudio. 
Debido a la variedad de las características composicionales del batolito de Aracataca se incluyen muestras de rocas representativas de cada facie, que integran la litología de este cuerpo intrusivo. También se tienen en cuenta las diferencias relacionadas con texturas, tamaño, forma y distribución de granos, el contenido mineral y las características distintivas observadas en el análisis microscópico y de difracción realizados.

La muestra DGL 001 corresponde a una roca ígnea plutónica de composición intermedia, y presenta características macroscópicas como: textura fanerítica, holocristalina con un tamaño de grano inequigranular, distribuido en cristales hipidiomórficos. Está constituida por una asociación de cuarzo, en una proporción de $30 \%$, feldespato potásico, presente en un $8 \%$, y plagioclasas $42 \%$, como minerales formadores principales y otros minerales secundarios y accesorios como las biotitas, hornblendas y alteraciones en las plagioclasas de sericitas y epidotización. Teniendo en cuenta los porcentajes de los minerales a partir del diagrama de Streckeisen 1976, la roca se clasificó como una Granodiorita (ver Figura 5).

Al realizarse los análisis microscópicos a la sección delgada, se encontró que esta muestra perteneciente a la facie Granodiorita se compone en mayor proporción por cristales inequigranulares, en tanto que la forma de los cristales minerales varía de subhedral a anhedral y describe una textura hipidiomórfica, principalmente integrada por minerales de cuarzo $(30 \%)$ y plagioclasas (40\%), que exhibían maclas polisintéticas de tipo labradoritas, así como textura pertítica, representando el mineral más abundante en la muestra de roca y feldespato potásico $(10 \%)$ con alteraciones e intercrecimiento en forma de enrejado propias de las microclinas, que corresponde a un tipo de feldespato y se presenta en la muestra de roca en menor proporción. Como minerales secundarios y accesorios se diferencian biotitas $(8 \%)$, hornblenda $(2 \%)$; cristales de clorita $(4 \%)$, sericita $(3 \%)$ y actinolita (1\%), que se asocian a la alteración de la plagioclasa y de la biotita, y en menor abundancia, minerales opacos (2\%). (ver Tabla 1$)$. 


\begin{tabular}{|c|c|c|c|c|c|c|c|c|c|}
\hline \multirow{2}{*}{$\begin{array}{c}\text { Muestra } \\
\text { Dgl 001 }\end{array}$} & \multicolumn{2}{|c|}{$\begin{array}{c}\text { Minerales } \\
\text { esenciales }\end{array}$} & \multicolumn{3}{|c|}{$\begin{array}{c}\text { Minales } \\
\text { secundarios }\end{array}$} & \multicolumn{3}{|c|}{ Minerales de alteración } \\
\cline { 2 - 9 } & Qz & Pl & Fsp & Hb & Bt & $\begin{array}{c}\text { Min } \\
\text { opacos }\end{array}$ & Chl & Sericita & Actinolita \\
\hline $\begin{array}{c}\text { Contenido } \\
(\%)\end{array}$ & 33.3 & 44.4 & 11.1 & 2.2 & 8.8 & 2.2 & 4.4 & 3.3 & 1.1 \\
\hline
\end{tabular}

Tabla1.

Distribución de la composición mineralógica de la muestra DGL 001 a partir del análisis microscópico de la sección delgada, perteneciente a la Facie de Granodiorita Batolito de Aracataca. La nomenclatura está basada en Abbreviations for names of rock-forming minerals [4].

Los cristales de cuarzo presentes en la granodiorita tienen formas subhedrales a anhedrales, incoloros y con tamaño de grano fino a medio $(1-3 \mathrm{~mm})$, relieve bajo, inclusiones de minerales y presencia de fracturas, algunos con zonación de afuera hacia adentro, lo que indica un cambio en la composición del cristal. A lo largo de la sección se observan cristales de plagioclasas, principalmente subhedrales, con tamaños que van de fino a medio $(1.5-3.5 \mathrm{~mm})$, relieves bajos, colores de interferencias negros en su posición de extinción, y blanco en su posición de máxima iluminación, color real-incoloro, exhibiendo maclas polisintéticas de composición labradorita debido a su ángulo de extinción que varían de 30 a $40^{\circ}$. Las plagioclasas se observan alteradas a sericita y poseen inclusiones pertitas que hacen referencia a texturas de exsolucion de un feldespato sódico (plagioclasa sódica) dentro de un cristal de feldespato potásico.

Los cristales de feldespato potásico se presentan de forma subhedral a anhedral, incoloros, con una deformación plástica y maclas enrejilladas de tamaños medios $(2 \mathrm{~mm})$, relieves bajos, colores de interferencia negros, gris o blancos. Por otra parte, el ángulo de extinción paralela indica la presencia de microclina con inclusiones de albita, exhibiendo a la vez inclusiones pertíticas.

Los minerales accesorios están representados por cristales de biotita, hornblenda y minerales opacos. La hornblenda se presenta en forma anhedral de color verde a amarillento, con relieve medio a bajo, presencia de fracturas y algunas inclusiones 
de minerales opacos. La biotita es tabular, con bordes rectos e irregulares de forma subhedral y con clivaje basal. Además, es de color verde claro a café y pleocroica. La clorita se observa como producto de la alteración de la biotita; este mineral con formas subhedral a anhedral y tamaño de grano fino $(1-1.5 \mathrm{~mm})$ y color verde claro; de igual forma, la plagioclasa altrera la sericita, tiene forma subhedral a anhedral, es incolora y de tamaño de grano fino, con birrefringencia que varía entre rosados y amarillos de primer orden. Los minerales opacos tienen un tamaño de grano muy fino $(<0.1 \mathrm{~mm})$ con formas subhedrales, color negro, isotrópicos y distribuidos de manera aleatoria sobre toda la sección delgada

Figura 5.

(A) Muestra macroscópica de la Granodiorita (DGL 001). (B) A la derecha se observa la sección delgada de la muestra DGL 001 y a la izquierda la muestra DGL 001 vista en el estereoscopio. (C) Sección delgada DGL 001 vista en nicoles paralelos, se diferencia el contenido de los principales minerales como cuarzo $(\mathrm{Oz})$, plagioclasa

$(\mathrm{Pl})$, microclina $(\mathrm{MC})$, Biotita (Bt), clorita (Chl). (D) Sección DGL 001 vista en nicoles cruzados, en la imagen se logra diferenciar una microclina (Mc) con estructura enrejada y maclas polisintéticas relacionada con un tipo de feldespato, se observa también la plagioclasa (PI) alterada con textura pertítica y, por último, la biotita (Bt), alterando a clorita (Chl). (E) comprende la sección delgada DGL 001 vista en nicoles paralelos, se diferencia el contenido de los principales minerales como cuarzo $(\mathrm{Oz})$, plagioclasa (PI), biotita (Bt), y sericita (Ser). (F) Sección DGL 001 vista en nicoles cruzados, en la imagen se diferencia la alteración de la plagioclasa a sericita y su textura pertítica, y la biotita no presenta alteración en este caso, se diferencia en sus totalidades características: amarillo oscuro a café y habito laminar. La nomenclatura utilizada está basada en Donna L. Whitney and Bernard W. Evans (2010).

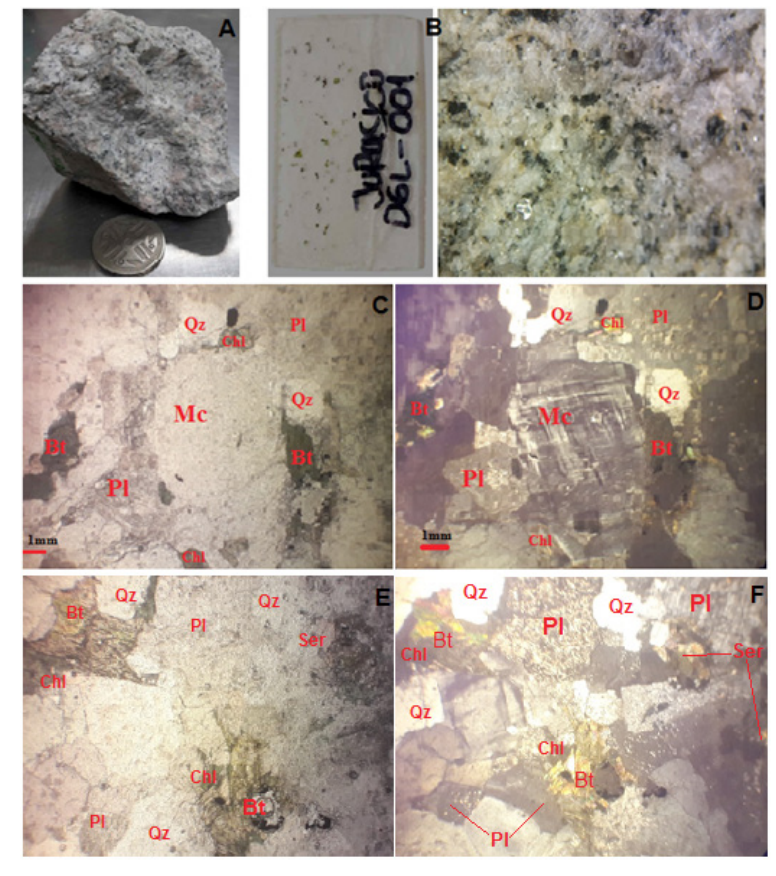


Asimismo, con la descripción macroscópica se obtiene el análisis realizado a la muestra (DGL 021), correspondiente a la facie Cuarzomonzonita, la cual presenta textura fanerítica, su grado de cristalinidad es holocristalino, con forma hipidiomórfica y sus minerales se distribuyen entre sistemas inequigranulares y equigranulares. En cuanto a su composición y propiedades mineralógicas, las rocas se constituyen por: cuarzo $18 \%$, feldespato potásico $41 \%$, y plagioclasa $26 \%$ como minerales principales. Respecto a minerales secundarios, se observaron hornblendas, biotitas, y alteraciones de estos minerales principales como cloritas y sericitas. A partir del diagrama de Streckeisen (1976), la muestra se clasifico como una Cuarzomonzonita (ver Figura 7). Microscópicamente, esta facie corresponde a una roca compuesta por cristales inequigranulares, cuya forma varía de anhedral a subhedral y está constituida principalmente por cristales de cuarzo $(20 \%)$, plagioclasas $(25 \%)$, exhibiendo estas maclas polisintéticas en estructura enrejada de tipo labradoritas, y feldespato potásico (41\%) con incidente alteración a microclina en la totalidad de la muestra; en este caso los minerales accesorios en menor proporción son biotita $(6 \%)$ y hornblenda $(1 \%)$ y identificándose minerales alterados de biotita y plagioclasa como clorita $(3 \%)$ y sericita $(2 \%)$, respectivamente; también se observaron minerales opacos $(3 \%)$ y algunas inclusiones en minerales principales como el cuarzo (ver Tabla 2).

\begin{tabular}{|c|c|c|c|c|c|c|l|l|}
\hline \multirow{2}{*}{$\begin{array}{c}\text { Muestra } \\
\text { Dgl 001 }\end{array}$} & \multicolumn{3}{|c|}{$\begin{array}{c}\text { Minerales } \\
\text { esenciales }\end{array}$} & \multicolumn{3}{c|}{ Minales secundarios } & \multicolumn{2}{|c|}{$\begin{array}{c}\text { Minerales de } \\
\text { alteración }\end{array}$} \\
\cline { 2 - 8 } & Qz & Pl & Fsp & Hb & Bt & $\begin{array}{c}\text { Min } \\
\text { opacos }\end{array}$ & Chl & Sericita \\
\hline $\begin{array}{c}\text { Contenido } \\
(\%)\end{array}$ & 23.5 & 29.4 & 47 & 1 & 5 & 3 & 4 & 2 \\
\hline
\end{tabular}

\section{Tabla2.}

Distribución de la composición mineralógica de la muestra DGL 021 a partir del análisis microscópico de la sección delgada, perteneciente a la Facie de Granodiorita Batolito de Aracataca. La nomenclatura está basada en Abbreviations for names of rock-forming minerals [4]. 
Los cristales de cuarzo presentes en la granodiorita tienen formas variadas y se muestran con estructura anhedral y ocasionalmente subhedral. Son de carácter incoloro, de relieve moderado en un color de interferencia blanco del primer orden y tamaño de grano entre muy fino a medio $(0,25 \mathrm{~mm}$, $0,38 \mathrm{~mm}, 1,7 \mathrm{~mm}, 2,4 \mathrm{~mm})$, con un relieve moderado. Se presentan fracturas considerables en la mayoría de los cristales y algunos se muestran con zonación de afuera hacia adentro, indicando un cambio en la composición del cristal a lo largo de la sección se observan cristales de plagioclasas principalmente subhedrales, con tamaños que van de fino a medio $(1,3 \mathrm{~mm}$, $2 \mathrm{~mm}$ y 2,3 mm), con relieves medios a bajos, sus colores de interferencias son negros en su posición de extinción y blanco en su posición de máxima iluminación, color real-incoloro, exhibiendo maclas polisintéticas de composición labradorita debido a su ángulo de extinción, que varía de 28 a $40^{\circ}$. Las plagioclasas se observan alteradas a sericita y con inclusiones de textura pertíticas que hacen referencia a texturas de ex-solución ricas en potasio, las cuales predominan sobre los cristales ricos en sodio. Se observó además que este mineral consiste en una alteración producida por un óxido de hierro, por lo que aparece en él una textura de reacción característica de una Ilmenita.

Los cristales de feldespato potásico se presentan de forma anhedral a subhedral, incoloros, con maclas enrejilladas. Se diferencian tamaños de fino a medio $(1 \mathrm{~mm}, 1,7 \mathrm{~mm}$ y $3 \mathrm{~mm})$, relieves bajos a medio, y colores de interferencia negros, gris o blancos, lo que hace posible asociarlos con alteraciones a microclina, teniendo en cuenta además los colores de interferencia y la estructura y textura del mineral. Por otra parte, se identifican inclusiones de albita y texturas pertíticas. Los minerales accesorios están representados por cristales de biotita hornblenda y minerales opacos. La hornblenda se presenta en forma de anhedrales de color verde a café, con relieve medio a bajo. La biotita es tabular, con bordes que pueden ser rectos $\mathrm{y}$ en ocasiones irregulares, se presenta de forma subhedral, clivaje basal, color de café a verde olivo con granos de tamaño fino $(0,24 \mathrm{~mm}-0,7 \mathrm{~mm})$. Además, se observa la clorita como producto de la alteración de la biotita, 
que presenta formas anhedrales a subhedrales y con tamaño de grano fino y color verde claro. Por último, se diferencian cristales de sericita correspondientes a la alteración de la plagioclasa, la cual tiene forma subhedral a anhedral, es incolora y de tamaño de grano fino, con birrefringencia que varía entre rosados y amarillos de primer orden. Los minerales opacos también tienen un tamaño de grano fino $(0,35 \mathrm{~mm}-0,7 \mathrm{~mm})$ con formas subhedrales, color negro, isotrópicos y se distribuyen de manera aleatoria sobre toda la sección delgada.

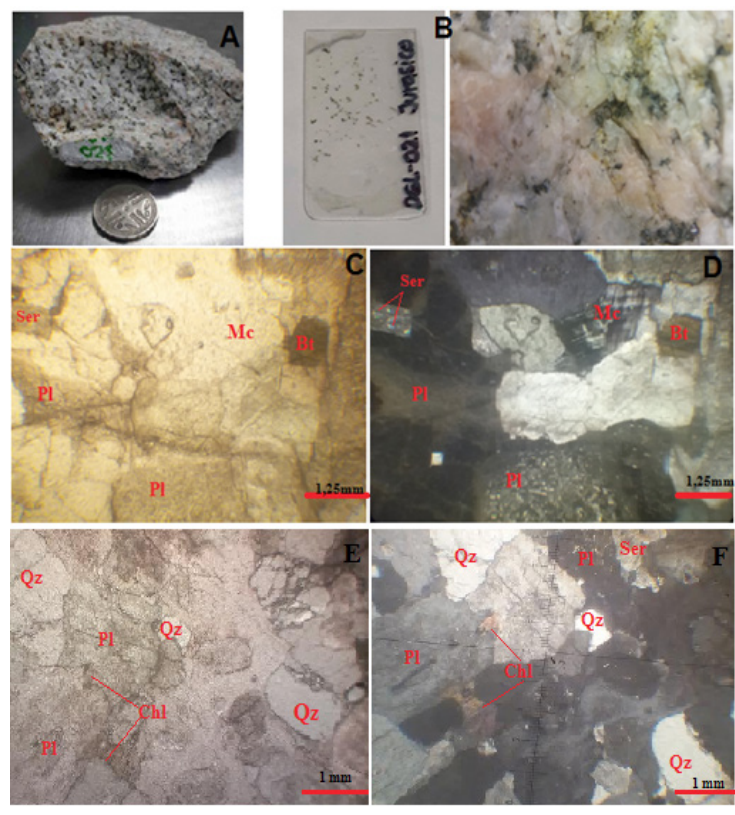

\section{Figura 6.}

(A) Muestra macroscópica DGL 021. (B) A la derecha se observa la sección delgada de la muestra DGL 021, y a la izquierda la muestra DGL 021 vista en el estereoscopio. (C) Sección delgada DGL 021 vista en nicoles paralelos, se diferencia el contenido de los principales minerales como cuarzo (Oz) plagioclasa (Pl), microclina (Mc), biotita (Bt) y sericita (Ser). (D) Sección DGL 021 vista en nicoles cruzados, en la imagen se diferencia una microclina $(\mathrm{Mc})$ con estructura enrejada y maclas polisintéticas, relacionada con un tipo de feldespato alcalino, el cual se distribuye en poca proporción en la muestra, también se observa la plagioclasa (PI) alterada con textura pertítica, y por último se observa un cristal de sericita que corresponde a alteración total de una plagioclasa. (E) Sección delgada DGL 021 vista en nicoles paralelos, se diferencia el contenido de los principales minerales como cuarzo (Qz), plagioclasa (Pl), clorita (Chl) y sericita (Ser). (F) Sección DGL 021 vista en nicoles cruzados, se diferencian cristales de plagioclasa (PI) alterada con textura pertítica, cristales de sericita por la alteración de la plagioclasa y clorita (Chl), producto de la alteración total de los minerales de biotita (Bt). La nomenclatura utilizada está basada en Whitey y Bernard [4]. 
Macroscópicamente, la facie de Tonalitas, muestra DGL 019, corresponde a una roca ígnea plutónica de composición intermedia, leucocrática con textura fanerítica distribuida en sistemas equigranulares con tamaños de granos gruesos, donde las formas cristalinas son predominantemente hipidiomórficas. Está constituida por cristales de cuarzo (40\%), plagioclasas (58.7\%) y feldespato potásico (menor a un 5\%) . En cuanto a sus minerales secundarios está constituida por biotitas $(10 \%)$ y hornblendas (2\%). Además, en la muestra se observan alteraciones de sertizacion en las plagioclasas y algunas biotitas alterando a cloritas (4\%). Microscópicamente, en la facie Tonalita, en sección delgada de esta muestra, se diferencian cristales equigranulares con formas que varian entre subhedrales y euhedrales, describiendo una textura hipidiomórfica. A partir del diagrama de Streckeisen 1976, corresponde a una Tonalita (ver Tabla 3).

\begin{tabular}{|c|c|c|c|c|c|c|c|c|c|}
\hline \multirow{3}{*}{$\begin{array}{r}\text { Tabla } 3 . \\
\text { Distribución de la composición } \\
\text { mineralógica de la muestra } \\
\text { DGL } 019 \text { a partir del análisis } \\
\text { microscópico de la sección } \\
\text { delgada, perteneciente a la Facie } \\
\text { de Tonalita Batolito de Aracataca. } \\
\text { La nomenclatura está basada } \\
\text { en Abbreviations for names of } \\
\text { rock-forming minerals [4].of rock- } \\
\text { forming minerals [4]. }\end{array}$} & \multirow{2}{*}{$\begin{array}{l}\text { Muestra } \\
\text { Dgl } 001\end{array}$} & \multicolumn{3}{|c|}{$\begin{array}{l}\text { Minerales } \\
\text { esenciales }\end{array}$} & \multicolumn{3}{|c|}{ Minales secundarios } & \multicolumn{2}{|c|}{$\begin{array}{l}\text { Minerales de } \\
\text { alteración }\end{array}$} \\
\hline & & Qz & $\mathrm{Pl}$ & Fsp & $\mathrm{Hb}$ & $\mathrm{Bt}$ & $\begin{array}{l}\text { Min } \\
\text { opacos }\end{array}$ & Chl & Sericita \\
\hline & $\begin{array}{c}\text { Contenido } \\
(\%)\end{array}$ & 37.5 & 60 & 2.5 & 2 & 10 & 2 & 4 & 2 \\
\hline
\end{tabular}

Las tonalitas se encuentran conformadas por cristales de cuarzo con formas euhedrales a subhedrales, son incoloros y con tamaño de grano fino a medio (0.3-1.2 mm). Algunos de ellos poseen bordes redondeados, relieve bajo y sin fracturas. Las plagioclasas se muestran en cristales de forma subhedral, que presentan una distribución inequigranular y un tamaño de granos que variía 
de medio a grueso (1-5mm). Se observaron tipos de plagioclasas principalmente andesinas y labradoritas, clasificadas según sus características texturales y la diferenciación del ángulo de extinción $\left(27-42^{\circ}\right)$. Este mineral evidencia maclas polisintéticas. Se identificaron cristales de albita con textura pertítica. Una de las características de estos minerales es su alto grado de alteración a sericita, en tanto que el feldespato potásico resulta escaso en la sección delgada.

La biotita está representada por cristales subhedrales y hábito tabular de grano fino (0.5-1 mm). Presenta un clivaje basal y color verde claro con pleocroísmo, que varía entre tonalidades verdosas y café claro. Estos cristales exhiben alteración a clorita con inclusiones de minerales opacos. La hornblenda se observa con cristales subhedrales, de grano fino $(0.8-1 \mathrm{~mm})$ y color café verdoso a verde amarillento. Presenta pleocroísmo y relieve bajo. Los minerales opacos que la constituyen muestran cristales de forma anhedral con un tamaño de grano muy fino, isotrópicos, que se encuentran como inclusiones en minerales como las biotitas y hornblendas.

Los minerales de alteración son principalmente clorita y sericita. La clorita tiene forma subhedral y un color verde oscuro, presentando pleocroísmo con tamaño de grano fino, mineral de alteración producto de la biotita. La sericita es incolora, con formas anhedrales, observándose en forma de diseminaciones sobre los cristales de plagioclasa.

La muestra DGL 019 se encontraba en contacto intrusivo con un cuarzogabro, diferenciado por su composición, textura, coloración y variación en el tamaño de grano. Se considera que ambas facies pudieron haberse formado en el mismo tiempo, pero la composición del magma produjo cambios en las facies. El cuarzogabro referido corresponde a una roca ígnea plutónica de composición intermedia, con textura fanerítica, distribuida en sistemas equigranulares con tamaño de grano finos de forma predominantemente hipidiomórficas. La roca está constituida por cuarzo (15\%), plagioclasa $(50 \%)$ y menos del $5 \%$ de feldespato potásico, acompañados de biotitas y hornblendas como minerales máficos. En la muestra se observan alteraciones de sertización en las plagioclasas y biotitas que alteran a cloritas. 
Microscópicamente, la sección delgada se constituye en su mayoría por cristales equigranulares, caracterizados en su mayoría por la presencia de plagioclasas $(45 \%)$, cuarzo $(15 \%)$, biotitas y hornblendas como minerales mayoritarios en la muestra, observándose, además, plagioclasas de tipo labradoritas y bytownitas con maclas polisintéticas que sufren alteraciones por sericitización. El feldespato potásico (1\%) en la lámina es muy escaso, por lo que representa menos del $5 \%$ de la roca. En cuanto a los minerales accesorios, aparecen: biotita (15\%), alterando a clorita (5\%), hornblenda $(15 \%)$ y minerales opacos ( $2 \%)$. La forma de los minerales varía de subhedral a anhedral y describen una textura hipidiomórfica, clasificada, a partir del diagrama de Streckeisen (1976), como un cuarzogabro.

\begin{tabular}{|c|c|c|c|c|c|c|c|c|c|}
\hline \multirow{3}{*}{$\begin{array}{r}\text { Tabla } 4 . \\
\text { Distribución de la composición } \\
\text { mineralógica de la muestra } \\
\text { DGL 019-2 a partir del análisis } \\
\text { microscópico de la sección } \\
\text { delgada, perteneciente a la } \\
\text { Facie de Granodiorita Batolito de } \\
\text { Aracataca. La nomenclatura está } \\
\text { asada en Abbreviations for names }\end{array}$} & \multirow{2}{*}{$\begin{array}{l}\text { Muestra } \\
\text { Dgl } 001\end{array}$} & \multicolumn{3}{|c|}{$\begin{array}{l}\text { Minerales } \\
\text { esenciales }\end{array}$} & \multicolumn{3}{|c|}{ Minales secundarios } & \multicolumn{2}{|c|}{$\begin{array}{c}\text { Minerales de } \\
\text { alteración }\end{array}$} \\
\hline & & Qz & $\mathrm{Pl}$ & Fsp & $\mathrm{Hb}$ & $\mathrm{Bt}$ & $\begin{array}{l}\text { Min } \\
\text { opacos }\end{array}$ & Chl & Sericita \\
\hline & $\begin{array}{c}\text { Contenido } \\
(\%)\end{array}$ & 24.5 & 73.7 & 1.6 & 15 & 15 & 2 & 5 & 2 \\
\hline
\end{tabular}

El cuarzogabro se encuentra conformado por cristales de cuarzo con formas euhedrales a subhedrales, incoloros, con tamaño de grano fino (0.3-1 mm), relieve bajo y con algunas fracturas. Las plagioclasas se presentan en cristales subhedrales con distribución inequigranular y con tamaño de grano medio a grueso (1-5mm). 
La composición de las plagioclasas es de tipo labradorita con un ángulo de extinción de $\left(38-40^{\circ}\right)$ y maclas de Carlsbad con textura pertita. Una de las características de estos minerales es su alto grado de alteración a sericita. El feldespato potásico es bastante escaso en la sección delgada.

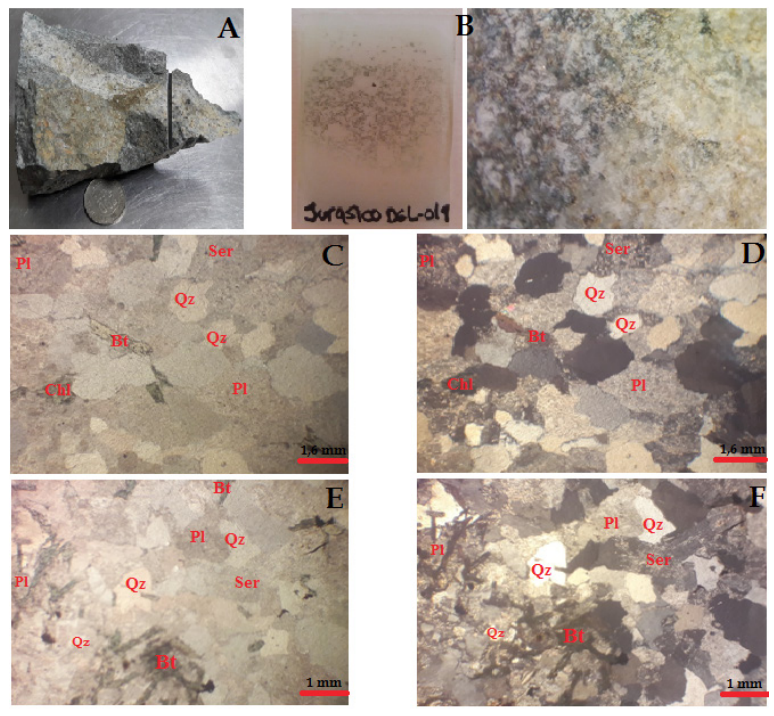

Figura 7.

(A) Muestra macroscópica DGL 019.

(B) A la derecha se observa la sección delgada de la muestra DGL 019 y a la izquierda la muestra DGL 019 vista en el estereoscopio. (C) Sección delgada DGL 019 vista en nicoles paralelos, se diferencia el contenido de los principales minerales como cuarzo $(\mathrm{Qz})$, plagioclasa $(P I)$, biotita (Bt) y sericita (Ser). (D) Sección DGL 19, también se observa en esta la plagioclasa (PI) alterada con textura pertitica, $y$, un cristal de sericita que corresponde a alteración total de una plagioclasa. Las imágenes $E$ y $F$ corresponden a la intrusión presente en la muestra entre una roca tonalita y un cuarzogabro (E) Sección delgada DGL 019 vista en nicoles paralelos, se diferencia el contenido de los principales minerales como cuarzo (Qz), plagioclasa (Pl), y sericita (Ser). (F) Sección DGL 019 vista en nicoles cruzados, se diferencian cristales de plagioclasa (Pl) alterada con textura pertítica y cristales de sericita por la alteración de la plagioclasa. La nomenclatura utilizada está basada en [4]. 
Por su parte, la biotita está representada por cristales subhedrales con tamaño de grano fino $(0.5-1 \mathrm{~mm})$, presenta un clivaje basal y color verde claro con pleocroísmo que varía de tonalidades verdosas a café claro. Estos cristales exhiben un grado de alteración a clorita, y presentan inclusiones de minerales opacos. La hornblenda tiene forma subhedral a anhedral, con tamaño de grano fino $(0.8-1 \mathrm{~mm})$, color café verdoso y relieve bajo. Los minerales opacos se presentan en cristales anhedrales con un tamaño de grano muy fino, isotrópicos, los cuales se encuentran como inclusiones en minerales como biotitas y hornblendas.

Los minerales de alteración son principalmente clorita y sericita. La clorita tiene formas subhedrales, de color verde oscuro. Presenta pleocroicoismo y tamaño de grano fino; este mineral es el producto de alteración de la biotita. La sericita es incolora, con formas anhedrales, que le dan un aspecto sucio a los minerales, es el mineral producto de alteración de las plagioclasas.

Las alteraciones propias de las biotitas y plagioclasas hacen parte de un reemplazamiento de estos fenocristales por cristales de alteración que corresponden a clorita y epidota respectivamente. A este tipo de alteración se le denomina Propilítica (Gifkins et al, 2005) en [5] y son apreciadas en las muestras (DGL 001, DGL 019, DGL 021). Por otra parte las asociaciones de cuarzo, sericita y pirita se han reconocido remplazando casi la totalidad de la los fenocristales de plagioclasa son propias de alteraciones sericíticas. Esta información se incluye de forma preliminar, esto se debe a que los datos de forma detallada no son un objetivo al alcance de este artículo. 


\section{Ensayos de difracción DRX}

Los ensayos de difracción fueron aplicados a dos muestras correspondientes a la Facie Granodiorita y a la Facie Cuarzomonzonita. Durante la aplicación del ensayo DRX se tuvieron en cuenta resultados proporcionados por análisis cuantitativos y cualitativos. Los análisis cualitativos de las fases presentes en los especímenes seleccionados de las muestras se realizaron mediante la comparación de los perfiles observados con los perfiles de difracción reportados en la base de datos PDF-2 del International Centre for Diffraction Data (ICDD). Los análisis cuantitativos de las fases encontradas se realizaron mediante el refinamiento (ajuste de los picos de difracción) por el Método de Rietveld entre los perfiles observados (Perfil de Difracción = gráficos de difracción observados) y los perfiles de difracción reportados en la base de datos International Centre for Diffraction Data (ICDD). Los porcentajes reportados corresponden a la relación entre las fases policristalinas refinadas sin considerar el porcentaje de material amorfo. El porcentaje de las fases que no pudieron ser identificadas se encuentran dentro del material amorfo no determinado.

\section{Facie Granodiorita}

A partir de los datos cuantificables de los minerales formadores de roca, se confirma que la muestra DGL 0001 es una granodiorita. En concreto, los resultados del ensayo de difracción estiman que el contenido de moscovita es mayor respecto al de minerales de biotita (ver Tabla 5). Estos datos sugieren que se trata de una roca de composición más acida que intermedia.

No existen, por demás, representaciones mineralógicas potenciales, pero se evidencian tres indicios de alteraciones hidrotermales: en primer lugar, 
la cloritización en las biotitas que forman minerales de clinocloro; en segundo lugar, se identificó calcita en baja proporción, lo que sugiere pulsos hidrotermales con flujos de composiciones físicoquimicas que pueden relacionarse con fluidos circulantes, a través de microfracturas que cristalizaron minerales carbonatados; $y$ en último lugar, la albita tratada térmicamente indica una génesis de formación a altas temperaturas o un fluido hidrotermal que interviene luego de su formación (ver Figura 9).

Tabla 5.

Fases cristalinas identificadas con ayuda de la base de datos PDF-2 del International Centre for Diffraction Data (ICDD) en el especimen seleccionado de la muestra con código interno E3JG.

\begin{tabular}{|c|c|c|c|c|}
\hline \multicolumn{2}{|r|}{ FASE } & PDF No. & NOMBRE & CUANTITATIVO \\
\hline \multirow{8}{*}{ Cristalino } & $\mathrm{SiO}_{2}$ & $010-85-0796$ & Cuarzo & $32,3 \%$ \\
\hline & $\begin{array}{c}\mathrm{K}_{0.96} \mathrm{Na}_{0.04} \mathrm{Al}_{\mid} .71 \mathrm{Fe} 0.29\left(\mathrm{Al}_{0.9 \mid}\right. \\
\left.\mathrm{Si}_{3.09} \mathrm{O}_{10}\right)(\mathrm{OH})_{1.78} \mathrm{~F}_{0.22}\end{array}$ & $010-73-9861$ & Moscovita-2MI & $4,5 \%$ \\
\hline & $\mathrm{K}_{0.96} \mathrm{Na}_{0.04} \mathrm{Al} \mathrm{Si}_{3} \mathrm{O}_{8}$ & $010-83-1895$ & Microclina & $12,4 \%$ \\
\hline & $\mathrm{Mg}_{2.5} \mathrm{Fel}_{.65} \mathrm{Al}_{1.5} \mathrm{Si}_{2.2} \mathrm{Al}_{1.8} \mathrm{O}_{10}(\mathrm{OH})_{8}$ & $010-89-2972$ & Clinocloro IMIa & $0,8 \%$ \\
\hline & $\mathrm{Ca}\left(\mathrm{CO}_{3}\right)$ & $010-80-2811$ & Calcita & N.C \\
\hline & 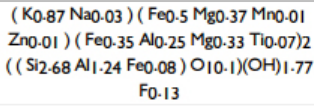 & $010-76-8339$ & Biotita-IM & $1,2 \%$ \\
\hline & $\left(\mathrm{Na}_{0.75} \mathrm{Ca}_{0.25}\right)\left(\mathrm{Al}_{1.26} \mathrm{Si}_{2.74} \mathrm{O}_{8}\right)$ & $010-76-0926$ & Albita cálcica & $39,8 \%$ \\
\hline & $\mathrm{Na}\left(\mathrm{Al} \mathrm{Si}_{3} \mathrm{O}_{8}\right)$ & $010-89-6427$ & $\begin{array}{l}\text { Albita tratada } \\
\text { térmicamente }\end{array}$ & $9.0 \%$ \\
\hline
\end{tabular}

Figura 8. Análisis comparativo por difracción de rayos- $X$ de las fases identificadas en el especimen seleccionado de la muestra con código interno E3JG. En el perfil de difracción experimental se observaron reflexiones con poca intensidad que no pudieron ser asignadas a alguna fase reportada [6].

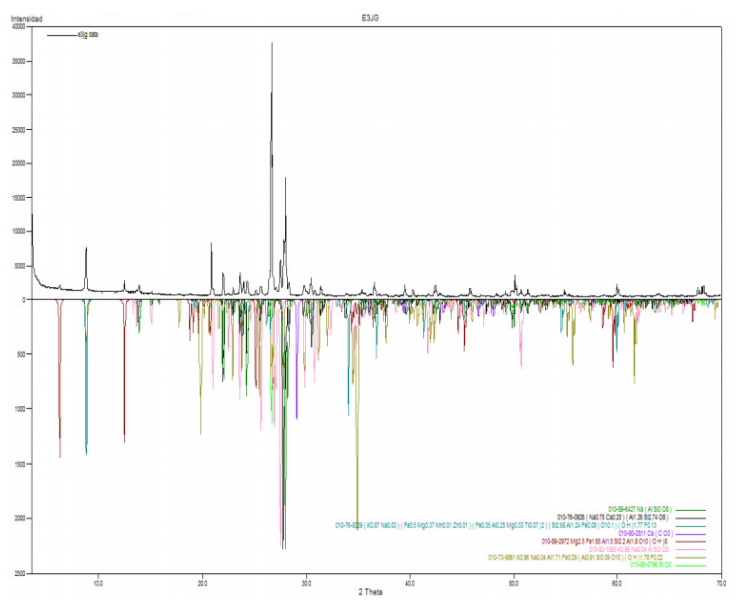




\section{Facie Cuarzomonzonita}

A partir de los datos cuantificables de los minerales formadores, se determinó que el mineral con mayor contenido en la muestra DGL 021 es la albita. Este además es considerado como el más propenso a sufrir alteraciones, alcanzando a producir sericita, que facilita la desintegración parcial de la roca.

Los minerales de feldespato potásico, al estar asociados a minerales de biotita y a minerales como cuarzo, sericita, clorita y hematita, estimulan una alteración hidrotermal donde la biotita sufre cloritización y se altera el feldespato potásico como la microclina. A su vez, estos son reemplazados por hematitas, cloritas de la alteración de minerales ferromagnesianos y carbonatos como la calcita.

\begin{tabular}{|c|c|c|c|c|}
\hline \multicolumn{2}{|r|}{ FASE } & PDF No. & NOMBRE & CUANTITATIVO \\
\hline \multirow{7}{*}{ Cristalino } & $\mathrm{SiO}_{2}$ & $010-85-1054$ & Cuarzo & $27,0 \%$ \\
\hline & $(\mathrm{Na0} .98 \mathrm{Ca}-02)\left(\mathrm{Al}_{1.02} \mathrm{Si}_{2.98} \mathrm{O}_{8}\right)$ & $010-70-3752$ & Albita & $44.7 \%$ \\
\hline & $\mathrm{K}_{0.92} \mathrm{Na}_{0.08} \mathrm{Al}_{0.99} \mathrm{Si}_{3.01} \mathrm{O}_{8}$ & $010-76-0830$ & Microclina & $16.5 \%$ \\
\hline & $\mathrm{Mg}_{2.5} \mathrm{Fel} .65 \mathrm{Al}_{1.5} \mathrm{Si}_{2.2} \mathrm{Al}_{1.8 \mathrm{O}_{10}(\mathrm{OH}) 8}$ & $010-89-2972$ & Clinocloro IMIa & $3,6 \%$ \\
\hline & $\begin{array}{l}\mathrm{K}_{0.92} \mathrm{Na}_{0.08} \mathrm{Al}_{1.86} \mathrm{Fe}_{0.14} \mathrm{MgO}_{80.02}( \\
\left.\mathrm{Al}_{0.97} \mathrm{Si}_{3.03} \mathrm{O}_{10}\right)(\mathrm{OH})_{1.91} \mathrm{~F}_{0.09}\end{array}$ & $010-73-9860$ & Moscovita-2MI & $7,4 \%$ \\
\hline & $\mathrm{Ca}\left(\mathrm{CO}_{3}\right)$ & $010-86-2343$ & Calcita & $0,8 \%$ \\
\hline & $\mathrm{Fe}_{2} \mathrm{O}_{3}$ & $010-73-2234$ & $\alpha$-Hematita & N.C \\
\hline
\end{tabular}

Tabla 6.

.Tabla 6. Fases cristalinas identificadas con ayuda de la base de datos PDF-2 del International Centre for Diffraction Data (ICDD) en el especimen seleccionado de la muestra con código interno E3JH. . 
Las alteraciones hidrotermales para este tipo de minerales sugieren que el transporte del fluido fue favorecido por la presencia de fracturas en la roca, generándose penetraciones de fluidos mineralizadores o flujos de composición físico-químicas variables que originan diferentes alteraciones, como el caso de las hematitas y las cloritas.

Figura 9.

Análisis comparativo por difracción de rayos- $X$ de las fases identificadas en el espécimen seleccionado de la muestra con código interno E3JH. En el perfil de difracción experimental se observaron reflexiones con poca intensidad que no pudieron ser asignadas a alguna fase reportada [6].

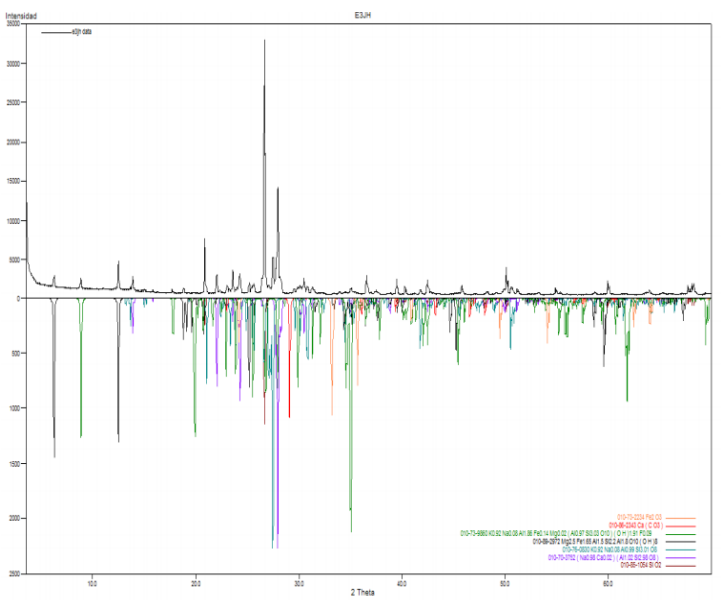




\section{Discuciones}

El análisis petrográfico detallado permitió determinar los tipos de asociaciones de los minerales contenidos en las muestras estudiadas dentro de las variaciones litológicas presentes en el Batolito de Aracataca, al Este del municipio de Fundación, Magdalena. En esta región predominan rocas ígneas plutónicas, principalmente diferenciadas en Granodioritas, Cuarzomonzonitas y Tonalitas sin delimitaciones o contactos evidenciables entre sus distribuciones de facies. Las observaciones y resultados obtenidos durante los estudios que se realizaron (análisis macroscópicos, microscópicos y DRX) evidencian que los cambios y alteraciones de los minerales están asociados a los eventos magmáticos sufridos durante su proceso de formación y al dominio de fluidos hidrotermales.

Asimismo, los análisis microscópicos y macroscópicos coinciden en el hecho de que las muestras de roca contienen alteraciones propilíticas y sericíticas en minerales de feldespato, plagioclasas y biotitas, principalmente, las cuales se relacionan con la incidencia de alteraciones hidrotermales que ocasionan recristalización en la roca de nuevos minerales con comportamientos más estables ante las condiciones de los fluidos hidrotermales. Es por esto que se producen modificaciones en la composición original de la roca.

En todas las muestras (DGL 001, DGL 019, DGL 021) se presentan texturas de ex-solución en las estructuras de cristales de plagioclasa. Este tipo de texturas se asocia a fluctuaciones en la temperatura que tuvieron lugar durante la fase de cristalización de la roca, por lo que se produjo una desmezcla en el magma, característica que se relaciona con la diferenciación de las facies que componen el Batolito de Aracataca. Estas características conllevan a sostener que el Batolito de Aracataca se formó en un mismo tiempo geológico, pero posee diferenciación de magmas de diferente composición, por lo cual es diferenciado en facies. El análisis cualitativo y cuantitativo realizado por DRX arrojó que los minerales de alteración, en todas las muestras, son principalmente clorita reemplazando la biotit;, andesina y albita reemplazando la plagioclasa; y microclinas reemplazando el feldespato potásico. Con este ensayo se identificaron minerales en pequeñas proporciones, producto de las alteraciones hidrotermales como clinocloro, en respuesta a minerales de anfíboles y biotitas, así como hematita, relacionada con 
las texturas de reacción en respuesta a la presencia de óxidos de hierro en la roca en mínimas cantidades, por lo que no fue posible cuantificarlo. El alto contenido de albita en las muestras se atribuye a cristalizaciones realizadas a altas temperaturas. Cuando las temperaturas disminuyen se producen exsoluciones, que se separan del resto de minerales en la segmentación magmática y se adhieren a cristales de feldespato potásico o forman pertitas en las asociaciones con plagioclasas [7].

Algunos minerales de cuarzo en las muestras DGL 001 Y DGL021 presentaron características como zonación y fracturamiento, indicando con ello un aumento en la velocidad de cristalización del magma durante los procesos del enfriamiento de las soluciones en el magma y la reacción de la roca ante estos procesos $[8,9,10]$. El fracturamiento presente en los minerales de cuarzo en la muestra DGL O21 está asociado a una cristalización de la roca a lo largo de la zona de falla, que además se relaciona con los movimientos tectónicos del lineamiento de la Falla Marimonda. 


\section{Conclusiones}

Las condiciones litológicas composicionales de las muestras descritas en el artículo poseen características variables relacionadas con la distribución, estructura y textura de los minerales contenidos. En los análisis de tipo macroscópico y microscópico estas condiciones litológicas incluyen cuarzos fracturados, minerales alterados y diferentes texturas de ex-solución, lo que las relaciona con los eventos geológicos a los cuales estuvo sometido la unidad Batolito de Aracataca durante su formación, y con la incidencia de actividades hidrotermales de baja temperatura a las cuales estuvo sujeto.

Las fracturas en los cuarzos pueden asociarse, por otro lado, con movimientos compresivos a los que estuvo sometido el cinturón magmático del Jurásico al cual pertenece la unidad Batolito de Aracataca.

Las alteracionesidentificadas fueron propilíticasen minerales como plagioclasas y biotitas, lo que se manifiesta principalmente como un reemplazamiento selectivo de fenocristales principales a epidota y clorita, respectivamente. Otro tipo de alteración identificada corresponde a las alteraciones sericíticas, evidenciadas en casi la totalidad de muestras estudiadas, por las asociaciones de sericita, cuarzo y pirita.

Finalmente, los análisis realizados a la muestra DGL 019 evidencian variaciones en su composición mineralógica y textural. Esto se relaciona con la presencia de intrusiones de roca pertenecientes a otro tipo de facie, condiciones que inducen a considerar que el Batolito de Aracataca sufrió variaciones en la actividad magmática, debido a la variedad compositiva de dicho magma.

La asociación mineralógica y las alteraciones presentes en el cuerpo ígneo evidencian que la petrogénesis del Batolito de Aracataca es correlacionable con los procesos que dieron origen al Cinturón de Batolitos Jurásicos [3]. Esta hipótesis se puede aceptar si se considera la composición y características de los estudios realizados al Batolito Central y al Batolito de Bolívar, los cuales indican que estos plutones sufrieron fluctuaciones composicionales en el magma, con episodios de alta profundidad, escasa velocidad de cristalización, emplazamientos y enfriamiento durante el proceso de intrusión [2]. 


\section{Referencias Bibliográficas}

1. J. M. Royero y J. Clavijo, "Mapa geológico generalizado del departamento Magdalena escala 1:300 000", Memoria Explicativa, 2000.

2. Ingeominas, Evolución geo histórica de la sierra nevada de santa marta, Bogotá, 2007.

3. C. Tschanz, R. Marvin, J. Cruz, H. Mehnert y G. Cebula, “Geologic Evolution of the Sierra Nevada de Santa Marta, Northeastem Colombia", Geol Soc Am. Bull, vol. 85, pp. 273-284,1974.

4. D. Whitney., y E. Bernard, "Abbreviations for names of rock-forming minerals", American Mineralogist, vol. 85, pp. 185-187, 2010.

5. N. Cruz, J. Carrillo., y L. Mantilla, "Consideraciones petrogenéticas y geocronología de las rocas ígneas porfiríticas aflorantes en la quebrada ventanas (municipio arboledas, norte de santander, colombia): implicaciones metalogenéticas", Boletín de Geología, vol. 36, p. 16, 2014.

6. J. Bonilla y J. Henao, Universidad industrial de Santander, Km. 2 Vía al Refugio Sede UIS-Guatiguará, Edificio de Investigaciones, Laboratorio de Rayos-X, Laboratorio 104, Piedecuesta, Santander, 2017.

7. A. Morosini, A. Ortiz y G. Ramos, Los granitoides famatinianos del sector suroccidental de la sierra de San Luis: clasificación y geotermometría, Asociación Geológica Argentina, vol. 64, no 3, p. 14, 2009.

8. N. Rubistein y M. Gargiulo, "Análisis textural de cuarzo hidrotermal del depósito El Pantanito, provincia de Mendoza: Nuevos aportes sobre su génesis", vol. 60, nº 1, 2005.

9. F. H. C. B, “Evolución geo histórica de la sierra”, 2007. [En línea]. 10. F. Rolón, "Opciones de la banca comercial en productos de importación", Dictamen Libre, no. 1213, pp. 71-75, 2013. 


\section{Este artículo se cita}

D. Corzo, G. Habid, L. Moscote., y L. Tapia, "Caracterización petrográfica del batolito de Aracataca sector sur- occidental de la Sierra Nevada de Santa Marta, Investigación e Innovación en Ingenierias, vol. 5, $\mathrm{n}^{\circ} .2$, pp. 78-109., 2017 